\title{
O PROCESSO DE CRIAÇÃO DO MONUMENTO NATURAL DO RIO SAMBURÁ (MG): DEFINIÇÃO DE ESTRATÉGIAS DE USO PÚBLICO OU RATIFICAÇÃO DE INTERESSES PRIVADOS?
}

\author{
Mikael Fonseca Lemos ${ }^{1}$ \\ Paula Fernandes da Silva ${ }^{2}$
}

\section{RESUMO}

Unidades de Conservação são áreas delimitadas que têm como objetivo, entre outros aspectos, a proteção da biodiversidade, dos recursos naturais ou de determinadas feições singulares, como é o caso da proposta de criação do Monumento Natural do Rio Samburá. Estudos recentes apontam que na bacia hidrográfica deste rio está contida a "nascente geográfica" do Rio São Francisco. A criação de unidades de conservação é fruto de esforços coletivos e discussões no interior da comunidade local, muita das vezes refletindo os interesses políticos de poder de determinada região, que influencia a expansão, redução ou até mesmo mudança na categoria de uma unidade de conservação, em questão. O presente artigo pretende discorrer sobre aspectos da história ambiental do Parque Nacional Serra da Canastra e os interesses que cercam a criação do Monumento Natural para a recém-descoberta nascente do Rio São Francisco. Entre eles, os possíveis motivos para a escolha deste tipo de unidade de conservação ao invés da expansão do Parque já existente, além de discutir estratégias de uso público da unidade de conservação.

Palavras chave: Rio Samburá; Rio São Francisco; monumento natural; nascente; Serra da Canastra; uso público.

\begin{abstract}
Conservation units are delimited areas whose main objectives are protection of biodiversity, natural resources or certain natural features. This article aims the proposal of the Rio Samburá's Natural Monument creation. Recent researches suggest this river is as a "geographic source" of the São Francisco River, leading to political pressures for the creation of this protected area whose main motivation would be the preservation of this spring, amid other possible aspirations. This article aims to discuss the best way to enable the public use for this area, based on the Management Plan of the Serra da Canastra National Park, which despite some land regularization problems, allows the realization of a good job as the preservation biodiversity and management of trails - thus attracting thousands of tourists every year interested to get closer to the nature.
\end{abstract}

Keywords: Samburá River; São Francisco River; natural monument; Serra da Canastra

\section{INTRODUÇÃO}

A região da Serra da Canastra que abrange a nascente histórica do Rio São Francisco, foi destino de diversas expedições desde o século XVI cujo objetivo era o desbravamento das áreas de cabeceira do rio. Contudo, o registro mais importante para o estudo histórico da

\footnotetext{
${ }^{1}$ Graduação em Geografia pela Universidade Federal Fluminense - E-mail: mikaellemos@id.uff.br

${ }^{2}$ Graduação em Geografia pela Universidade Federal Fluminense - E-mail: paulaa.fern@ gmail.com
} 
região foi feito apenas no século XIX pelo botânico francês Saint-Hilaire, pouco antes do estabelecimento do primeiro eixo de ocupação desta região, motivada pela crise da mineração de ouro nas Minas Gerais. Neste processo, colonos passaram a apropriar-se das terras que ainda encontravam-se isoladas, exterminando junto aos bandeirantes as comunidades indígenas e quilombolas, desenvolvendo atividades ligadas à pecuária bovina nas porções baixas de fundo de vale e, em menor escala, à mineração de diamante. O contexto das atividades econômicas se mantém de forma semelhante até a atualidade, uma vez que a principal delas gira em torno da produção de derivados do leite nas fazendas, concomitantemente às atividades de mineração, como a extração de diamantes e quartzito.

De acordo com o Sistema Nacional de Unidades de Conservação (SNUC), Parque Nacional é uma unidade de proteção integral que não admite uso direto de seus recursos naturais, sendo vetadas atividades de extração mineral. A estratégia para regulamentar essas atividades se deu a partir da criação de dois Projetos de Lei em 2007 (PL 1.448/07 e PL 1.517/07) liderados pelo deputado federal Carlos Melles (DEM/MG) na Câmara. O resultado prático foi a redução da área do Parque Nacional da Serra da Canastra (PNSC), assim como de parte da área urbana do município de São Roque de Minas (ver Anexo 1). Como contrapartida, foi criada uma Área de Preservação Ambiental (APA), categoria de uso sustentável, que permite atividades socioeconômicas e potencialmente impactantes. Ao desvincular áreas com intensas atividades humanas da categoria de proteção integral, a criação da APA permite gerir as mesmas de maneira independente, valorizando o hectare por exigir menos restrições ambientais. A resultante espacial do jogo de interesses fundiários da região é um mosaico ambiental, constituído de diversas unidades de conservação em descontinuidade e planos de manejo insuficientes que não dialogam entre si, e nem amenizam os impactos das atividades econômicas do entorno. Hoje, o debate central é a criação de um Monumento Natural para a área da recém descoberta nascente do Rio São Francisco, situada no município de Medeiros e as questões que se colocam são:

- Por que a escolha da categoria Monumento Natural (MONAT), unidade de proteção integral, numa região com diversidade de unidades de conservação?

- Quais os possíveis impactos dessa iniciativa nas atividades econômicas da região?

\section{Panorama geográfico da Serra da Canastra}

A área do PNSC está distribuída por em seis municípios (São Roque, Sacramento, Delfinópolis, São João Batista do Glória, Capitólio e Vargem Bonita), todos contidos no Estado de Minas Gerais (ver Anexo 2). Seu domínio morfoclimático corresponde ao Cerrado e sua geomorfologia é marcada pela alternância entre chapadões e vales, com a presença de campos limpos, e predominância de gramíneas no topo dos chapadões. Os campos limpos encontram-se atualmente em seu estágio de clímax por conta da reduzida atividade antrópica na área. Já os fundos de vale estão associados às matas ripárias à beira das drenagens, uma vegetação um pouco mais alta, claramente influenciada pelo domínio da Mata Atlântica. As drenagens escoam superficialmente em direção aos vales, formando quedas d'água em vários 
trechos, sobretudo no alto curso do Rio São Francisco, compondo exuberantes cenários e atraindo turistas que adentram o parque buscando contato com a natureza.

\section{Criação do Parque Nacional da Serra da Canastra (PNSC) e conflitos territoriais}

Após a aniquilação de comunidades indígenas e quilombolas ao longo dos séculos do Brasil Colônia, a região foi ocupada por garimpeiros, camponeses e fazendeiros, que trabalhavam em relação de interdependência. A atividade agropastoril servia como base alimentar para os garimpeiros, a extração de diamantes pagava uma porcentagem aos donos das terras de onde os mesmos foram extraídos, e uma parte dos camponeses da região trabalhava no garimpo nas épocas do ano com menor atividade na lavra.

A criação do PNSC ocorreu em 1972, por meio do Decreto $n^{\circ} 70.355$, com 200.000 hectares, sendo inicialmente dividida em duas partes por razões de planejamento: O Chapadão da Canastra, com 71.525 hectares, consolidado sob domínio do IBAMA e o Chapadão da Babilônia, com 130.000 hectares, mas sem a devida regulamentação fundiária. Por ser uma unidade de proteção integral, a atividade mineradora foi proibida e as atividades agropastoris foram restritas. A regulamentação fundiária serviu como subterfúgio para a expropriação de camponeses e fazendeiros de suas terras, sob alegação do INCRA de que as mesmas eram para fins de reforma agrária, e os seus proprietários foram indenizados com Títulos de Dívida Agrária.

$\mathrm{Na}$ mesma época foram desenvolvidas estratégias para a regularização da atividade mineradora de diamantes e quartzito, entrando em cena as mineradoras multinacionais que movimentam muito mais capital e alçaram o Brasil ao posto de $8^{\circ}$ exportador de diamantes do mundo. As mineradoras estrangeiras se apresentam como um ator com muito mais peso político para pressionar as ações dos órgãos estatais, caracterizando uma intervenção territorial verticalizante. $\mathrm{O}$ resultado foi a redução da área do parque coincidindo com os setores de extração de minério. A contradição entre as perspectivas de preservação é latente. De um lado o discurso da preservação de recursos e a expropriação de comunidades da área do parque, ao mesmo tempo em que se constatou a concordância dos órgãos ambientais e fundiários em relação às atividades altamente degradantes.

\section{Uso público}

Conforme determinado pelo SNUC, cada unidade de conservação deve dispor de um plano de manejo. O Plano de Manejo do PNSC, aprovado em 2005, é o instrumento responsável por regulamentar, entre muitos elementos, seu uso público. Dentre suas características, é possível destacar que a visitação é permitida e incentivada desde que dentro do horário de funcionamento do Parque.

O manejo de trilhas é bem realizado, havendo placas de sinalização e painéis de informação e localização distribuídos ao longo do parque, proporcionando simultaneamente educação ambiental, atividades lúdicas como banhos de cachoeira e caminhadas em meio a belas paisagens características do Cerrado. 
Existem restrições, e entre elas estão relacionadas o turismo de aventura: veículos automotores são proibidos mesmo nas áreas indenizadas, como forma de evitar a compactação dos solos locais, a degradação da flora e a ameaça à fauna silvestre, em sua maioria endêmica. A prática de esportes aquáticos é proibida em locais de ocorrência do patomergulhão, espécie em extinção. A prática de ciclismo é permitida nas estradas abertas à visitação, desde que os praticantes façam uso de equipamentos de segurança.

\section{Relações Hidrológicas entre o Rio São Francisco e o Rio Samburá}

No ano de 2002, a Companhia de Desenvolvimento dos Vales do São Francisco e do Parnaíba, vinculada ao Ministério da Integração Nacional, iniciou um estudo apoiado em técnicas de geoprocessamento sobre a real extensão do Rio São Francisco, tendo em vista as divergências bibliográficas quanto a esta informação. A prerrogativa do estudo sobre os recursos hídricos se apoia no interesse acerca da capacidade de produção de energia elétrica ao longo do curso do rio, que possui mais de uma usina construída, entre elas a de maior espelho d'água do país - a usina de Sobradinho. A criação de unidades de conservação no alto curso do rio tem a função de compensar os impactos ambientais gerados pela produção de energia, tanto na construção das hidrelétricas quanto das linhas de transmissão.

As imagens de satélite utilizadas neste estudo foram o elemento chave para mapeamentos que conduziram pesquisadores a formulação da tese de que a bacia hidrográfica do Rio Samburá abrangeria maior área geográfica que a bacia do Rio São Francisco (SILVA, et al. 2003), por conta do maior trecho percorrido desde sua nascente no Planalto do Araxá até a confluência entre os rios (Figura 1).

A pesquisa seguiu em campo, com a análise de mais três variáveis - talvegue, largura e vazão -, tanto em pontos referentes à nascente histórica, quanto na área que poderia vir a ser a nascente geográfica do rio. Os índices mais expressivos para as três variáveis foram observados em meio aos dados coletados no Rio Samburá. Desta forma, os rios São Francisco e Samburá, em um primeiro momento, respectivamente, principal e afluente, passariam a receber uma nova interpretação, que ao inverter a classificação atual conceberia o Samburá como o rio principal.

O estudo em questão ainda não se desdobrou em políticas públicas por parte dos órgãos ambientais nem tampouco foi incorporada ao ordenamento territorial da região. Contudo, a pressão na Câmara dos Deputados formalizou via PL 6.905/10 a criação do Monumento Natural do Rio Samburá, cujo objetivo seria proteger a nova nascente, integrando-a ao mosaico de unidades de conservação da Serra da Canastra. Diferentemente da nascente histórica do Rio São Francisco, que foi transformada em Monumento Natural em 2009, o projeto de 2010 para o Rio Samburá segue "aguardando parecer do relator na Comissão de Meio Ambiente e Desenvolvimento Sustentável”, conforme o site da Câmara. 


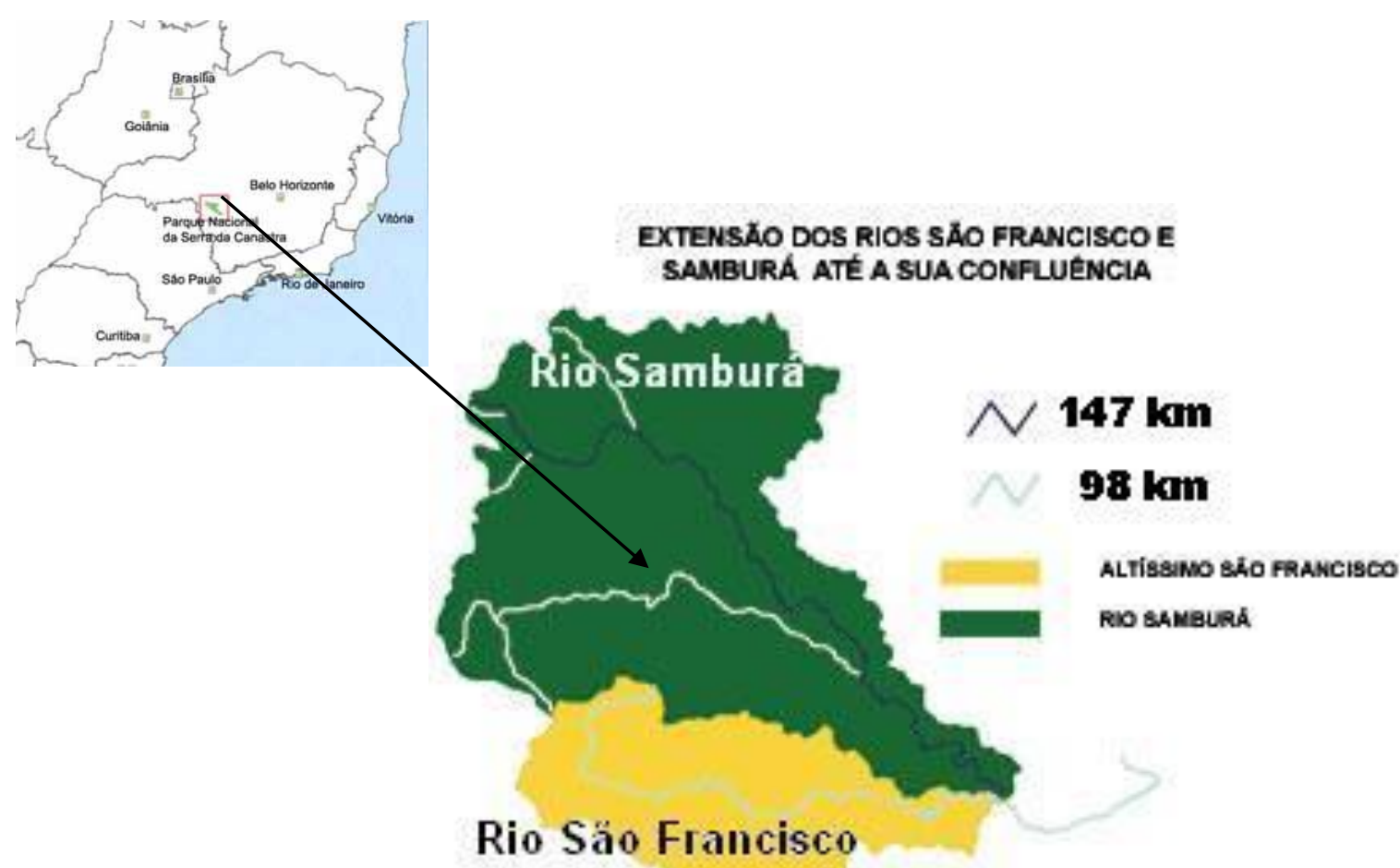

Figura 1: Imagem ilustrativa do percurso dos dois rios até a sua confluência (Fonte: www.gorgulho.com)

O debate em torno da "verdadeira" nascente do Rio São Francisco colaborou positivamente para a atividade turística na região, sobretudo em São Roque, que compreende a nascente histórica. Esta região não teria motivos para sair do roteiro turístico nacional, tendo em vista ser um dos principais atrativos do PNSC. É uma das principais portas de entrada no Parque e possui um trabalho consolidado de manejo de trilhas. Além disso, conta com a magnífica cachoeira da Casca D'Anta, um dos principais cartões postais da Serra da Canastra, juntamente à placa que indica o local exato onde o lençol freático aflora na superfície e escoa ao longo de aproximadamente $2.800 \mathrm{~km}$ até desembocar no oceano. No plano simbólico, o queijo da Canastra típico, tombado pelo IPHAN como patrimônio imaterial do Brasil, é mais um elemento que contribuiu social e culturalmente para a consolidação do território da Canastra.

Caracterização geográfica da região do alto curso do Rio Samburá e a proposta de criação do MONAT

A questão central em relação à criação deste Monumento Natural é que a nascente geográfica, situada no município de Medeiros, está afastada $15 \mathrm{~km}$ dos limites do PNSC e o 
texto do PL 6.905/2010 é muito claro em sua proposta. Seriam 9.356 hectares $^{3}$ integrados ao mosaico de unidades de conservação na forma de Monumento Natural do Rio Samburá - sem tratar da expansão dos limites do Parque ou da criação de zonas de amortecimento, provavelmente para não prejudicar as atividades econômicas vigentes na região. Para os autores do PL, o argumento fundamental para a escolha da categoria Monumento Natural é a presença de propriedades privadas no alto curso do Rio Samburá, que permite a moradia dentro da unidade de conservação e que pessoas desenvolvam atividades econômicas a partir de seus recursos, desde que de acordo com as determinações dos órgãos ambientais competentes.

"Uma das características que favorecem a criação deste tipo de unidade de conservação na área em questão é que ela "pode ser constituída por áreas particulares, desde que seja possível compatibilizar os objetivos da unidade com a utilização da terra e dos recursos naturais do local pelos proprietários" (art. 13)" (BRASIL, 2000 apud CMADS, 2010)

Considerando as informações sobre o uso e a cobertura do solo do Município de Medeiros (MG), este é caracterizado, em grande parte, por latifúndios e monoculturas, associadas às atividades econômicas locais. Grande parte da cobertura vegetal pioneira deu lugar a monoculturas de milho, batata e soja, o que resultou em solos nitidamente desgastados na região, corroborando com a tese de um cenário de concentração fundiária remanescente até então. Segundo dados do IBGE, referentes ao ano de 2010, o Município de Medeiros possuía uma população residente de 3.444 pessoas. A área de sua unidade territorial é de $936.437 \mathrm{~km}^{2}$, resultando em uma densidade demográfica de 3,64 habitantes $/ \mathrm{km}^{2}$. Este baixo índice de densidade demográfica e seu PIB per capta de R \$ 26.921,02 estão claramente associados a uma configuração espacial marcada pelo latifúndio e pela agropecuária.

\section{A categoria Monumento Natural e a viabilização do uso público}

O artigo 12 do SNUC define que o Monumento Natural tem como objetivo básico a preservação dos sítios naturais raros, singulares ou de grande beleza cênica, podendo ocupar propriedades particulares ou parte delas. Trata-se de uma unidade de Proteção Integral e, neste caso, preservaria a nascente do Rio Samburá, um sítio natural singular caracterizado por um ambiente que requer cuidados, uma vez que se encontra à montante da confluência com um dos mais importantes e extensos rios do país.

Os parágrafos 1,2 e 3 do artigo 12 se referem à compatibilização dos objetivos da unidade de conservação com o uso da terra e do aproveitamento dos recursos naturais locais pelo proprietário. Conforme frisado por LEUZINGER (2006) o monumento pode vir a se localizar sobre apenas uma pequena parcela da propriedade, o que não seria obstáculo para a exploração econômica desta, seja a partir de cultivos na própria terra, ou mesmo viabilizando

\footnotetext{
${ }^{3}$ Área aproximadamente três vezes menor os 26.715 hectares referentes ao Monumento Natural do Rio São Francisco.
} 
o uso público do Monumento aos turistas na forma de visitação ${ }^{4}$. O fato é que a nascente de um rio tende a ser um ecossistema peculiar e, por isso, deveria inspirar maiores cuidados. Caso a atividade econômica nesta propriedade esteja relacionada diretamente com a terra, como é o caso da agropecuária, a atenção deveria ser ainda maior, por conta do risco de degradação de mananciais via insumos químicos no alto curso do rio.

De modo geral, as atividades relacionadas ao uso público a serem instituídas nesta área, mesmo com base no plano de manejo do PNSC, poderão estar diretamente relacionadas com a geração de impactos ambientais, mesmo que estes sejam pouco significativos. Contudo, o incentivo de práticas relacionadas à educação ambiental pode vir a reduzir estes impactos. Externamente à área a ser delimitada como Monumento Natural do Rio Samburá, é possível que uma gestão eficiente das atividades turísticas gere empregos e renda para a população. Entretanto, a expectativa também é que se produza mais lixo, esgoto e aumente a demanda natural da região por água, comida e serviços.

\section{CONCLUSÃO}

Acredita-se que os estudos recentes e a proposta de criação do Monumento Natural do Rio Samburá não desqualificariam de forma alguma a identidade e a territorialidade da população local de São Roque - que direta ou indiretamente, sobrevivem da terra e da renda gerada pelo turismo de natureza. A problemática se dá, sobretudo, por conta da questão ambiental, que necessitará de fiscalização e rigor no manejo destas terras pela Unidade de Conservação.

Conforme observado pelo prefeito de Medeiros em uma discussão, um dos maiores entusiastas da criação desse monumento natural em seu município, o turismo ecológico vive um próspero momento refletido pelo crescimento no número de visitações a unidades de conservação nos últimos anos, e ele pode ser a chave para alavancar as atividades econômicas na região, como observado em outros Parques do Brasil. Para tal, é fundamental uma gestão despida de interesses privados 5 , que respeite as legislações ambientais vigentes e as respectivas categorias de manejo e, por fim, viabilize estratégias de uso público que contemplem concomitantemente as demandas do turista, a preservação de ecossistemas e o planejamento na exploração de recursos naturais, visando à sustentabilidade sem deixar de lado seus processos produtivos.

O processo de criação de uma unidade de conservação é fruto de pressões políticas de grupos que atuam sobre determinado território. O que queremos levantar no artigo é que os grupos que pressionam a criação de uma determinada unidade de conservação são os que

\footnotetext{
${ }^{4} \mathrm{Na}$ comparação entre categorias de manejo quanto ao aspecto das estratégias para viabilização do uso público, o Monumento Natural poderia ser comparado a uma Reserva Particular do Patrimônio Nacional, uma vez que para Leuzinger as RPPNs deveriam ter sido incluídas dentre as Unidades de Proteção Integral, eis que não é possível o uso direto de recursos naturais (...). (LEUZINGER, p.15)

5 Segundo reportagem do Jornal O Globo do dia 4 de agosto de 2010, tendo como maior exemplo o caso da tentativa de realização de compensação ambiental por meio da Fazenda Boa Vista, pertencente ao deputado Carlos Melles - grande representante político da oligarquia local e autor de outras propostas que visam alterar os limites do Parque Nacional da Serra da Canastra.
} 
possuem maior participação nas atividades econômicas desenvolvidas na região, atividades essas de uso intensivo e altamente degradantes (agronegócio e mineração). Entendemos que a criação da unidade de conservação visa, através do discurso de proteção dos recursos naturais, abrir espaço para mais um ramo de atividade econômica dos grupos hegemônicos da região, o turismo ecológico. Neste caso, a criação do Monumento Natural do Rio Samburá vai permitir a manutenção da propriedade privada, desde que assegurada em seu plano de manejo a mitigação de impactos das atividades econômicas ali desenvolvidas.

Acreditamos que, se de fato houvesse o interesse em preservar a nascente do Rio Samburá devido a sua importância ambiental, a melhor proposta seria a incursão da área no mosaico ambiental da região na forma de Parque Nacional, como forma de garantir o trânsito de espécies, a preservação de espécies endêmicas e a proteção da dinâmica ambiental.

Em relação ao uso público, o que podemos concluir é que as atividades relacionadas ao uso recreativo e outros usos indiretos dos recursos naturais das terras próximas à nova nascente do Rio São Francisco não apresentam um potencial de degradação que justifique a criação deste Monumento Natural - valendo a pena lembrar que toda nascente é considerada área de preservação permanente, obrigando sua preservação independentemente de pertencimento a unidades de conservação. Isto nos leva a crer que a principal motivação para a elaboração de tal unidade de conservação seria a valorização das terras ao seu entorno, apoiada nas atividades turísticas e na chegada das urbanidades a esta região.

\section{REFERÊNCIAS BIBLIOGRÁFICAS}

BRASIL. Plano de Manejo: Parque Nacional da Serra da Canastra. Brasília: MMA/IBAMA, 2005.

BRASIL. Sistema Nacional de Unidades de Conservação - SNUC. Lei nº 9985 de 18 de julho de 2000.2 disponível em: http://www.icmbio.gov.br/sisbio/images/stories/instrucoes_normativas/SNUC.pdf>

CMADS. Projeto de Lei $\mathrm{n}^{\circ}$ 6905/10. 2010. <disponível em: http://www.camara.gov.br/sileg/integras/997119.pdf>

FABRINI, F. Deputado Carlos Melles, autor de projetos que reduzem Parque Nacional da Serra da Canastra (...). Jornal O Globo online. Reportagem de 04/08/2010. <disponível em: http://oglobo.globo.com/politica/deputado-carlos-melles-autor-de-projetosque-reduzem-parque-nacional-da-serra-da-canastra-2970485\#ixzz3ZsnOSiyv>

FANZERES, A. Canastra a um passo do recorte. Reportagem da Revista Meio Ambiente de 06 /11/2008. <disponível em: http://www.revistameioambiente.com.br/2008/11/06/1467/>

FERREIRA, G. H. C. A regularização fundiária no Parque Nacional da Serra da Canastra e a expropriação camponesa: da baioneta à ponta da caneta - São Paulo, 2013. <disponível em: http://www.teses.usp.br/teses/disponiveis/8/8136/tde-30092013-112504/en.php>

GORGULHO, S. A Nova Nascente do Rio São Francisco. Reportagem do site de Silvestre Gorgulho. 201-. <disponível em: http://www.gorgulho.com/?sessao=materia\&idMateria=2\&titulo=A-NOVA-NASCENTE-

DO-RIO-SAO-FRANCISCO> 
LEUZINGER, M. D. Uso Público em Unidades de Conservação. 2006. <disponível em: http://www.nima.puc-

rio.br/aprodab/artigos/uso_publico_em_unidades_de_conservacao_marcia_leuzinger.pdf>

SILVA, P. A.; VIEIRA, G. G.; FARINASSO,M.; CARLOS, R. J. Determinação da Extensão do Rio São Francisco - Anais XI SBSR, 2003 < disponível em: http://www.sfrancisco.bio.br/arquivos/SilvaP001.pdf>

\section{Sites consultados:}

Site da Câmara dos Deputados <disponível em: http://www.camara.gov.br>

Site do Instituto Socioambiental (ISA) <disponível em: http://uc.socioambiental.org>

Reportagem do Jornal O Globo de 4 de agosto de 2010 <disponível em: http://oglobo.globo.com/politica/deputado-carlos-melles-autor-de-projetos-que-reduzemparque-nacional-da-serra-da-canastra-2970485>

Reportagem da Revista Meio Ambiente de 6 de novembro de 2011 <disponível em: http://www.revistameioambiente.com.br/2008/11/06/1467/> 


\section{ANEXOS}

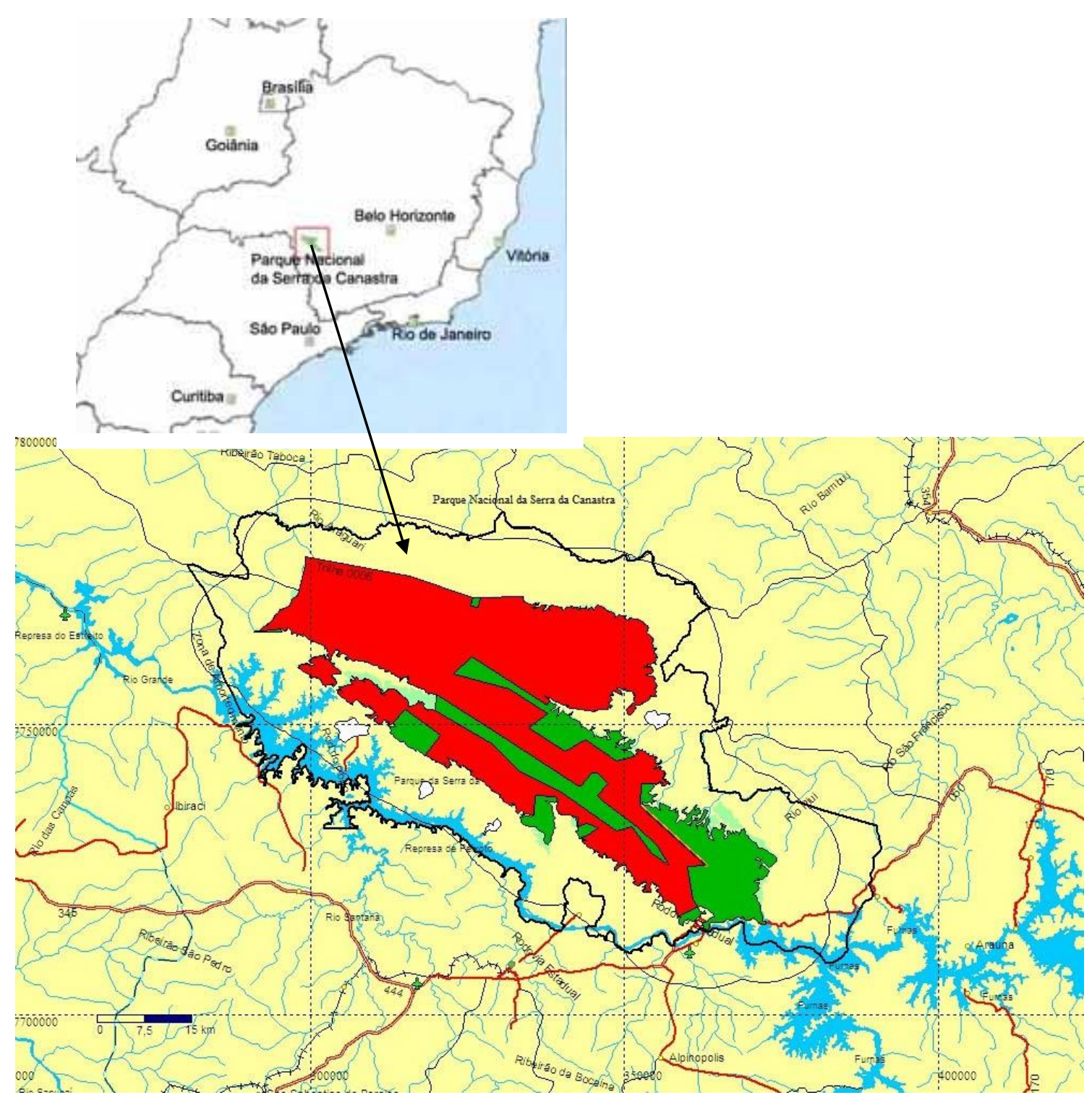

Anexo 1. Mapa com as áreas sujeitas à exclusão do Parque Nacional da Serra da Canastra em verde, por meio da PL 1.448/07, proposta pelo deputado Carlos Melles. 


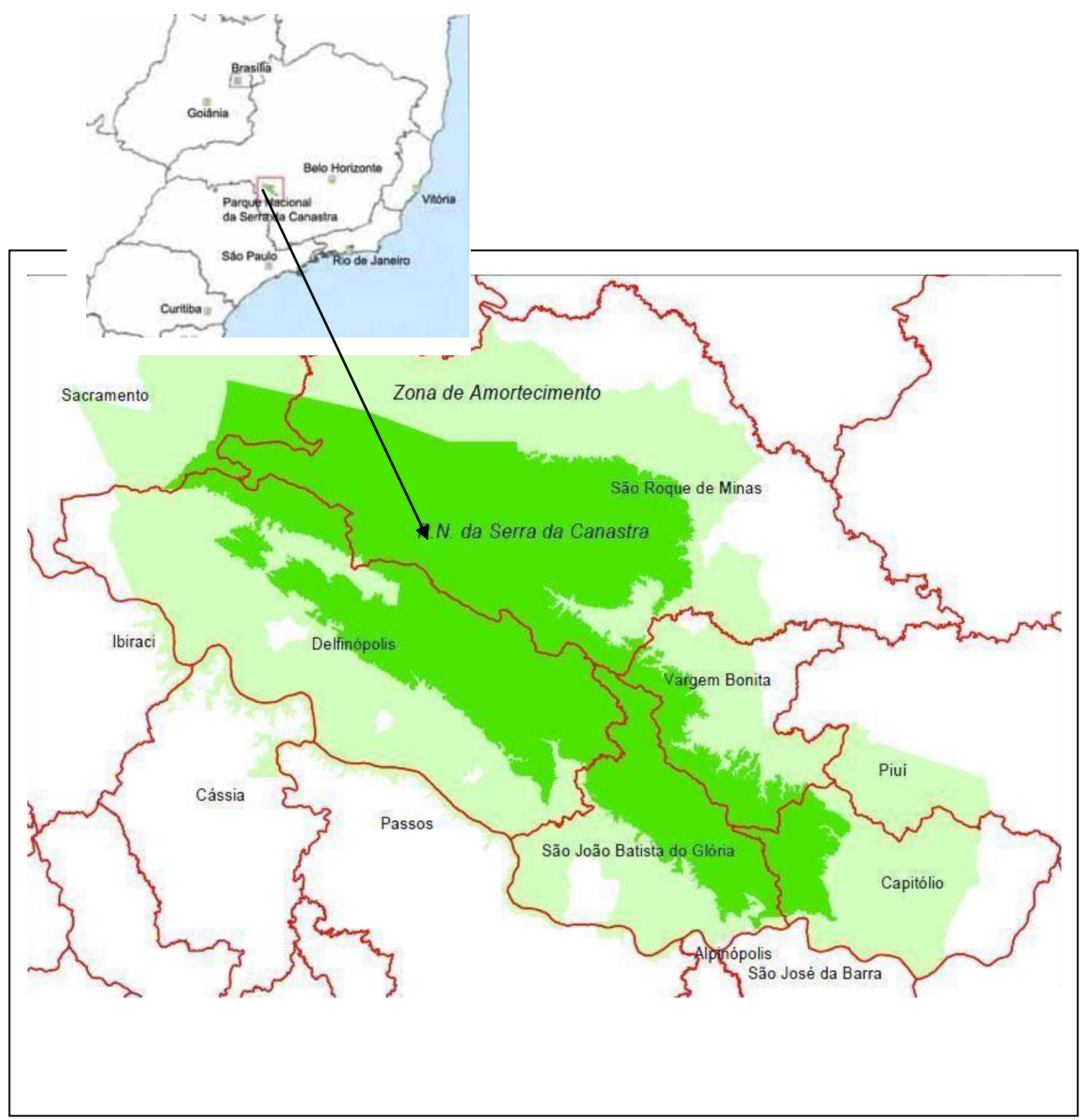

Anexo 2. Mapa dos municípios abrangidos pelo Parque e pela Zona de Amortecimento 